\title{
Study on Systematization of Construction Scheduling Method Structure of Construction Scheduling and its constitute Systems
}

\author{
Yoichi YUASA Yoshikazu SASAKI \\ Construction Technology Research \& Development Department, Takenaka Corporation \\ 1-5, 1-chome, Ohtsuka, Inzai, Chiba, 270-13, Japan
}

\begin{abstract}
Based on our experience, an emphasis in construction scheduling is not always same. Then we surveyed various opinions of construction engineers about construction scheculing. As a result it was clarified that methods of construction scheduling were different in each phase of projects and each type of projects. We classified construction phase into pre-execution stage, execution stage and post-execution stage, and construction type into ordinary method construction, construction in which adopted new method such as roof push-up method, large-scale construction and peculiar construction (PCa construction etc.). Further, we arranged examination contents in construction scheduling into the matrix composed of each phase and type. The other hand many types of computeraided construction scheduling systems have been developed, and some of them are now in wide-spread use. However because of the wide variety of construction projects and it is not necessarily said that those systems can be used effective for every project. This paper examines the needs for construction scheduling in various stages of many types of construction projects, discusses the structure of construction scheduling method, and introduces the outline of three systems developed based on this structure.
\end{abstract}

\section{Introduction}

Construction scheduling generally involves handling procectures and dates of execution, however, details of scheduling diverge in many ways. Now, a variety of computer systems for supporting scheculing have been developed and are in used. This paper discusses construction scheculing and the use of scheduling system and outlines of three systems developed based on such use.

\section{Structure of Construction Scheduling}

According to our experience, contents, method, and important points in construction schectuling are not always same. Therefore, we have surveyed the opinions of various construction engineers on scheculing. As a result, techniques for construction scheduling vary not only according to the phase and type of the project, but also depend on the department or person in charge of schectuling. Therefore, we have classified projects into three stages (pre-execution stage, execution stage and postexecution stage), and classified projects into four types (ordinary method construction, construction employing a new method, large-scale construction and peculiar construction (PCa construction, etc.)); and put the contents of the examination to be performed for each phase and type in the matrix shown in Table-1.

When we look at existing computer systems for scheduling, they are of limited use. However, the system cannot be said to be functioning fully as total schectuling in terms of the following points:

[1] Systems are concentrating with simple functions for preparing scheduling charts, etc., and not for serving as tools to support the whole scheduling operation.

[2] Items of data input increase with details of examination, and do not necessarily connect to man-power savings.

[3] The system is not constructed on the premises of a partial use of the system. Each application is difficult for a project not using all functions effectively.

In other words, a universal system that can cope with everything is not practical at the present stage of development. A system that has the ability to support each phase or type of examination as explained above is necessary for the present. In this case, the contents required of each system shall be to obtain effective data interlocking for independent purposes in each case. Outlines of the three systems, corresponding to the independent purpose, are explained below.

\section{A Scheduling System at pre-execution stage of Large-scale construction}

\subsection{Contents of Scheduling at pre-execution stage of Large-scale construction}

Large-scale construction requires not only designs considering construction, but also frequent changes of design are required for rationalization, rectuction of cost, and progress of technology. Moreover, as the scale becomes larger, labor and material requirements become enormous, so resource allocation is also an important point for construction in especially remote districts. Further, in a cold district area, reduction of work 
Table.1 Content of Construction Schectuling

\begin{tabular}{|c|c|c|c|}
\hline Stage & Pre-execution & Execution & Post-execution \\
\hline $\begin{array}{l}\text { Ordinary method } \\
\text { constniction }\end{array}$ & $\begin{array}{l}\text { 1. Choose construction method from } \\
\text { building specification and site } \\
\text { condition of the project. } \\
\text { 2. Make a master process based on } \\
\text { the chosen construction method. } \\
\text { 3. Calculate the resource quantities. }\end{array}$ & $\begin{array}{l}\text { 1. Examine construction work area } \\
\text { division. } \\
\text { 2. Make a cycle process. } \\
\text { 3. Make a whole process } \\
\text { considering resource allocation. } \\
\text { 4. Set a mile stone from the whole } \\
\text { process and make a detailed } \\
\text { process in the construction which } \\
\text { doesn't have repeat-ability. } \\
\text { 5. Make process charts for the } \\
\text { presentations and the } \\
\text { arrangements. }\end{array}$ & \multirow[t]{5}{*}{$\begin{array}{l}\text { 1. Based on the results of the } \\
\text { construction, order the process } \\
\text { and labor productivity ratio and } \\
\text { reflect those in the schectuling } \\
\text { after that. }\end{array}$} \\
\hline finishing work & . & $\begin{array}{l}\text { 1. Indicate in the work based on the } \\
\text { process charts according to } \\
\text { activity and the type of job. } \\
\text { 2. Grasp the progress situation of the } \\
\text { construction. }\end{array}$ & \\
\hline $\begin{array}{c}\text { construction adopting } \\
\text { a new method }\end{array}$ & $\begin{array}{l}\text { 1. Examine construction contents } \\
\text { based on the new construction } \\
\text { method. }\end{array}$ & $\begin{array}{l}\text { 1. Monitor the progress of the new } \\
\text { construction method and grasp } \\
\text { results. }\end{array}$ & \\
\hline $\begin{array}{l}\text { Large-scale } \\
\text { construction }\end{array}$ & $\begin{array}{l}\text { 1. Calculate execution quantity as far } \\
\text { as the stage that a design isn't } \\
\text { firmed is possible. } \\
\text { 2. Make a logical scheduling based } \\
\text { on the execution quantity. }\end{array}$ & $\begin{array}{l}\text { 1. Make the year, month and week } \\
\text { process charts while adjusting to } \\
\text { the plant construction. }\end{array}$ & \\
\hline $\begin{array}{c}\text { Peculiar } \\
\text { construction } \\
\text { (PCa construction) }\end{array}$ & $\begin{array}{l}\text { 1. Examine PCa applying extent } \\
\text { plan, PCa manufacturing plan } \\
\text { and PCa erection plan } \\
\text { mutually ,and decide the PCa } \\
\text { applying extent and the } \\
\text { manufacturing way. }\end{array}$ & $\begin{array}{l}\text { 1. By managing the manufacture of } \\
\text { the PCa member and the erection } \\
\text { process mutually, realize smooth } \\
\text { PCa production which doesn't } \\
\text { have the material arrangement } \\
\text { mistake and excessive stock. }\end{array}$ & \\
\hline
\end{tabular}

efficiency during winter due to wind and snow must also be considered. In an examination of the use of schechling, the general method is to calculate the quantity of each activity, set a labor productivity ratio corresponding to the activity, and determine the whole term considering restrictive conditions such as upper limit of labor force. It takes an enormous amount of time to calculate the quantity of each activity, and to create the whole scheduling for each design alternative, therefore, a sufficient examination is not being performed.

\subsection{Outlines of System}

This system consists of two sub-systems: one is a modeler that creates a building model through which each activity quantity can be calculated, and the other is a schechler that automatically prepares a schedule considering resource allocation calculated from the activity quantity, and an interface connecting the two sub-systems. It has the following specific features:

[1] Easy preparation of building model,

[2] Easy and accurate estimating of activity quantity based on building model,

[3] Automatic preparation of scheduling based on activity quantity and labor productivity ratio,

[4] Simulation function of resource allocation and process preparation.

\subsubsection{Modeler}

A sub-system can create a building model in a computer by inputting grid lines, span lengths, floor height, etc., and automatically calculates quantities of concrete and molds for a construction work area acoording to an arbitrary construction work area division, as shown in Fig.1 Fig. 4 . The modeler gives priority to grasping the rough quantity of activity at the pre- 
execution stage to create as simple a design as possible, therefore, it is different from an integrated system based on three dimensional $\mathrm{CAD}$ for building design as follows:

[1] Necessary members of building can be designed automatically by integrating general knowledge on structural design in the system.

[2] By ignoring detail of members such as shift grid line and cnter of the member, inputting time, and activity quantity calculating time are reduced.

[3] Data of above member can be changed of any using the crossing point of grid lines as the reference point, and then , the length of a member is automatically revised with the change of span length and the activity quantity can be recalculated immediately.

\subsubsection{Interface between Modeler and Scheduler}

The three basic activity quantities that a modeler can calculate directly are concrete quantities, mold quantities, and floor area. Quantities related to reinforcing bar quantity, steel frame quantity, quantities related to temporary work or finishing work are indirectly calculated using an experimentally obtained

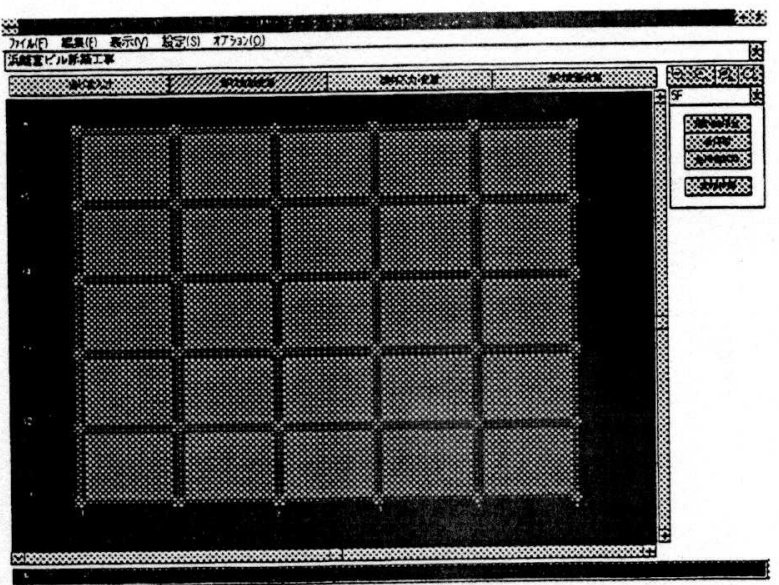

Fig.1 The screen to make members occur to automatically

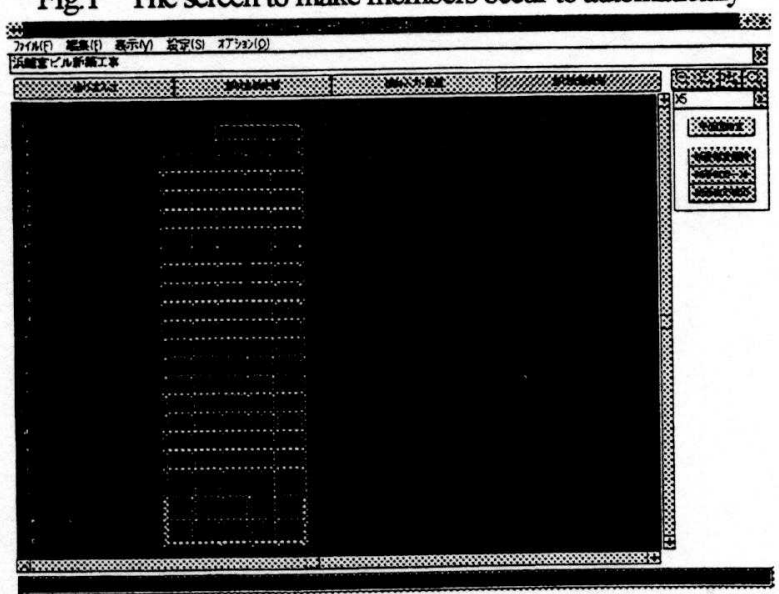

Fig.2 The screen of the building model section constant percentage studied (quantitative percentage) against the basic activity quantities, as shown in Fig. 5 . In this paper, two cases were applied, case one is to use the basic activity quantities automatically calculated from the modeler, and case two is to use an quantity calculated from quantitative percentage to basic activity quantities.

\subsubsection{Scheduler}

The scheculer is a sub-system for automatically making the

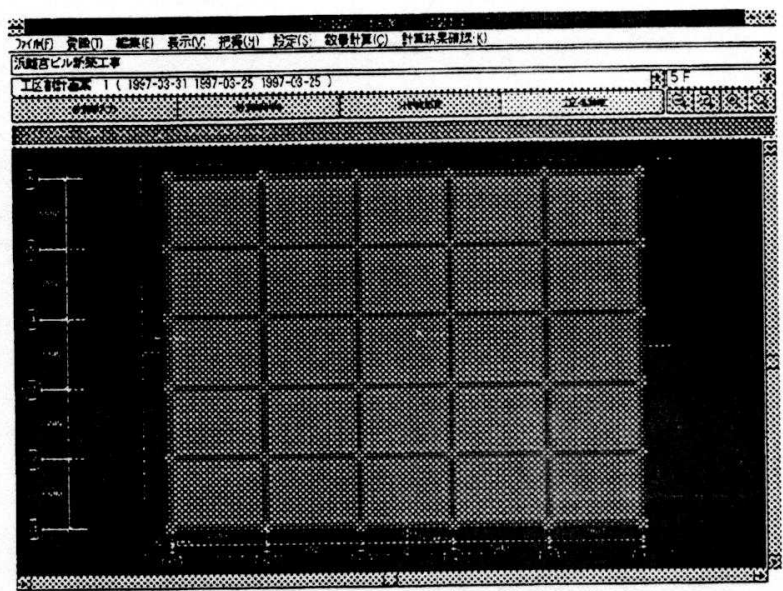

Fig.3 The screen of setting construction work area division

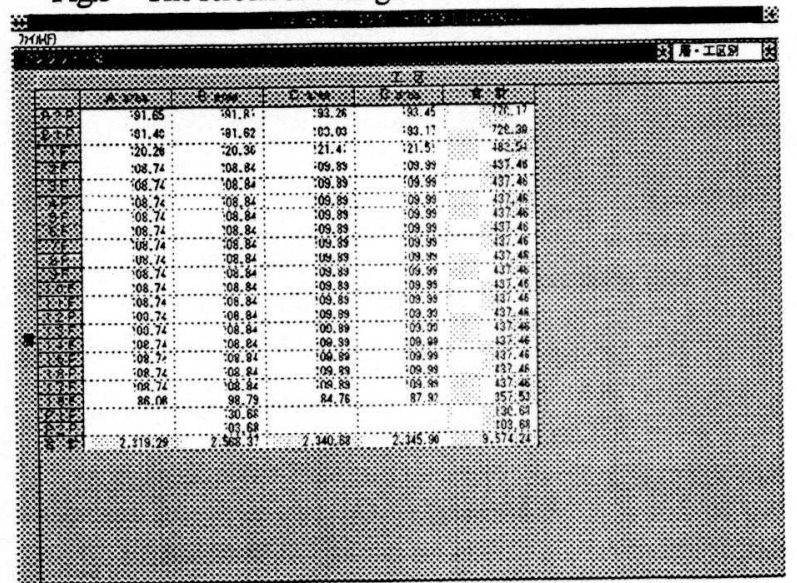

Fig.4 The screen to have multiplied activity quantity

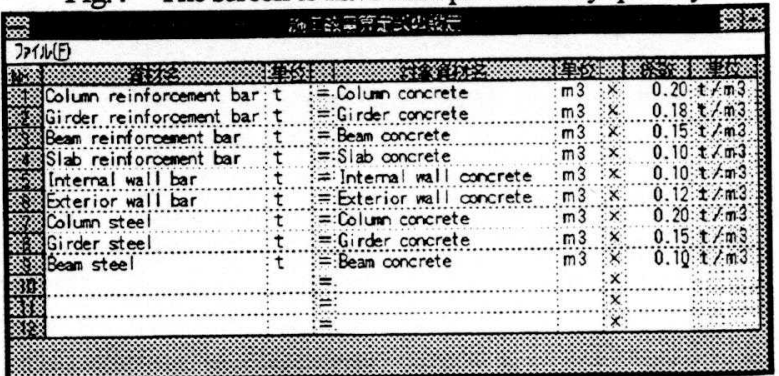

Fig.5 The screen of setting activity quantity computation formula 
total scheduling by setting the equation for calculating activity quantity, allocation of material and labor acoording to activity type, daily labor inputs, cycle process by construction work area, work orders between construction work areas, method of resource allocation, based on the basic activity quantities for the building calculated by the modeler etc., and consists of the modules below.

1) Setting Activity duration and Resource Allocation Method

Activity quantity, labor productivity, daily labor inputs, and activity duration have a trade-off relation-ship. With this module, one of two methods can be selected: one is the methods that increase or decrease activity duration according to the increase or decrease of labor productivity, and the other is to increase or decrease daily labor inputs, as shown in Fig.6. As for the recuction of work efficiency during winter in cold districts, two methods can be selected: a method of increasing inputs of labor only during that period or increasing labor uniformly including the period when work efficiency does not decrease.

\section{2) Preparation of Cycle Process}

Even with the same cycle process and work procedure, activity duration increases or decreases in a trade-off relationship with activity quantity and daily labor inputs. As shown in Fig7, preparations of cycle processes in this module only define the work procecture and the activity duration will automatically be calculated by the resources allocation method described above.

\section{3) Simulation of Preparing the Total Process}

The total scheduling is automatically made by setting the cycle process pattern and work relation for each construction work area in the table. At this stage, check the construction period and resource allocation, as shown in Fig.8. The scheduling must be changed when this value is outside the limit. The schectuling can be changed with a method that can be processed within the scheduler such as change of activity duration, work relation between construction work areas, change of cycle process (construction method), change of resource allocation method, and another method is to change construction work area divisions by the modeler. In this module, a new whole schechuling can be immediately and automatically prepared, therefore, a wide range of simulations becomes possible by combining this method.

\section{Scheduling System at execution stage of Ordinary Method Construction}

\subsection{Contents of Scheduling of Ordinary Method Construction}

The details of construction scheduling vary with the contents of project and progress as stated above. However, the scheduling to be performed throughout the project is considered to be basically the same. there are many cases at the construction

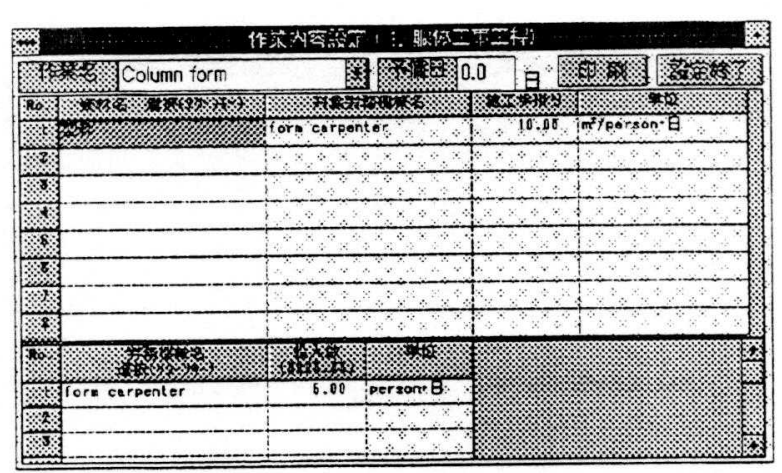

Fig.6 The screen of setting activity contents

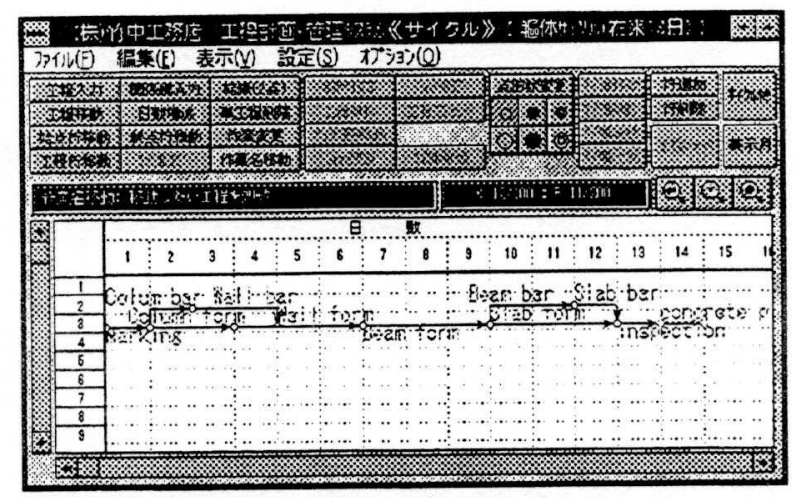

Fig.7 The screen of creating a cycle process

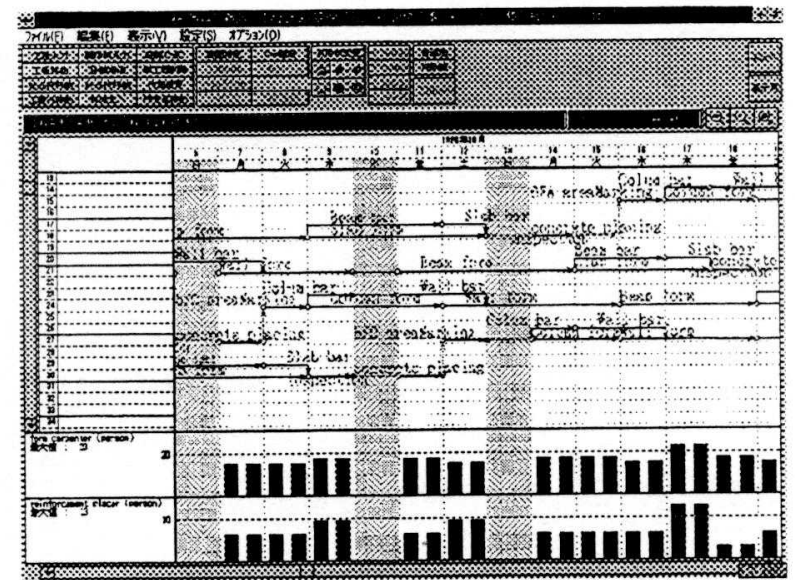

Fig.8 The screen of simulating a resource allocation

site where detailed scheduling is not required, or original schectuling is not yet performed sufficiently due to differences of ordering system or operating conditions. For example, the application levels of the system are various between only drawing the scheduling chart, and comparing the scheduling due to the differences in resource allocation and construction method. Moreover, two types of scheduling method exist: one is the "stack-up type" that calculate the construction period by examining the detailed activity and resouroes allocation, and the other is the "allocation type" that calculates the duration required 
for each unit of processes to achieve the target construction period, and examine the procedures and resources to cope with the duration. This method is processed comprehensively, within the meaning that the building processes finally coincide with each other. Further, as for the level of the "Outline Process" by which the project manager and the section manager control work observing the whole construction period and "Detailed Process" by which the person in charge of the work will plan partial processes or give instructions to workers, and coordination between these levels must be secured.

Therefore, the necessary condition for scheduling of ordinary method construction is to have high-grade scheduling including a simulation function such as for selecting the construction method to decide the work procedure, process allotment function for make-up process, stack-up simulation function, and resource allocation simulation necessary for preparing resources and labor, as well as the possibility of partial use of the system to match the system application level of the construction site.

\subsection{Outlines of System}

This system consists of four sub-systems: setting dictionary, setting resource relation, making process and scheduling chart, and printing. The system not only copes with the smallest activity level consisting of preparing a schectuling chart for clean written copy and with the level added functions of schectuling , allocation and stack-up of processes, resource allocation simulation, but can also be applied to preliminary schectuling examinations for support sections.

\section{1) Dictionary Setting Sub-system}

"Dictionary" in this paper means the vocabulary necessary for applying the system, and the convenience of the system is considered to be improved with fewer inputs. This sub-system not only prepares the terms of the standard floor construction work area, resources, labor, machines, and activity (shown in Fig.9), which can be applied in common in the construction site, but also allows terms to be freely added to the construction site. In addition, the off date of the construction site can be set for the day of the week, or case by case.

\section{2) Resource Relation Setting Sub-system}

Activity duration, daily input quantity of labor, machine and execution percentage have a trade-off relation-ship; therefore, a change of Activity duration must change the daily labor and machine input or labor productivity ratio. As shown in Fig10, this sub-system can automatically calculate the initial duration for each activity, by defining relations between resources necessary to activity, labor, machines and their quantity, and labor productivity ratio.

\section{3) Process Management Sub-system}

The scheduling are changed frequently. Therefore, the following functions were added to automatically follow up the logic of complicated scheduling, as well as considering the characteristics of computers:

[1] Can easily make a network process with the feeling of hand writing.

[2] Succoeding processes are automatically revised during process change.

[3] Hierarchical process of detailed process - Outline process is processed comprehensively.

[4] Automatically shift work afterwards in consideration of not only the off-date of the construction site, but also the offdates of material suppliers,

[5] Name of the activity to be stored independently and automatically, but can also be registered in the activity name dictionary.

[6] Combined processes of allocation and stack-up methods can be prepared for scheculing.

[7] Can simulate how the resources allocation changes with the change of process, as shown in Fig.11.

4) Making Scheduling chart and Printing Sub-system

The scheduling chart presents the contents of execution construction scheduling, and term of output and contents differ according to distribution and purpose. The screen of setting a schectuling chart format is shown in Fig. 12. This sub-system can not only present the contents of execution schectuling, it can edit and print a scheduling chart, and also prepare and print a clean scheduling chart, the lowest application level.

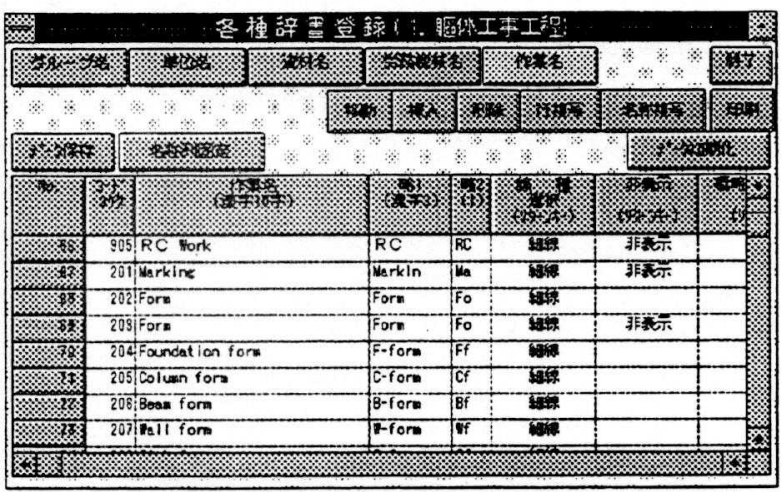

Fig.9 The screen of registering activities

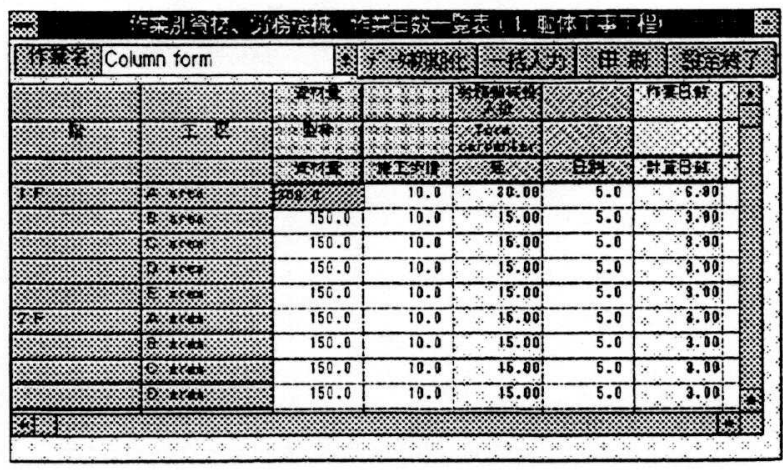

Fig.10 The screen which calculated the activity duration 


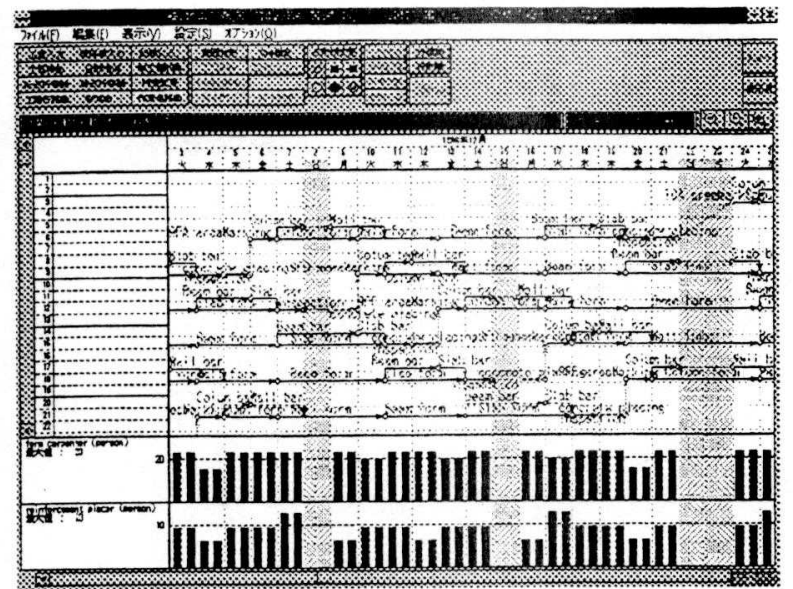

Fig.11 The screen of the process making and the resource allocation

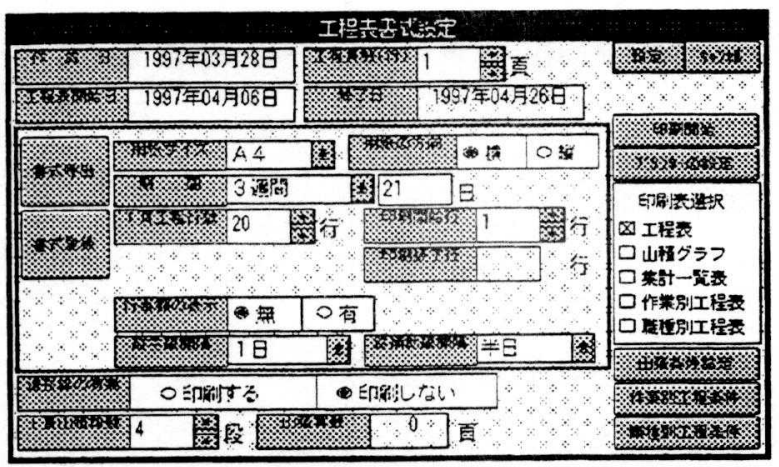

Fig.12 The screen of setting a scheduling chart format

\section{Scheduling System for Finishing Work at execution stage of Common construction}

\subsection{Outlines of Scheduling in Finishing Work}

Finishing work has following specific features in comparison to structural work:

[1] Work will be performed with the management unit of room or external facing, etc.

[2] Work must be performed within the restrictions of possible delay of structural work and fixed completion date.

[3] Works are within the building except exterior finishing work, and it is difficult to grasp progression status of the work.

[4] Because of the many job categories concerned, work instructions must be given for each job.

[5] Work order relation is not necessarily constant.

In finishing work, therefore, elements such as grasping progress status based on management unit, and work instructions for varieties of job category, are added to the common schectuling element. Under the present status, tables giving progress based for each managing unit and schectuling charts for each job category are prepared separately, in addition to the common scheduling chart, therefore, discrepancies in processes are frequently generated due to copying.

\subsection{Method of applying Scheduling chart in Finishing Work}

The common scheduling chart expresses floor and construction work area on the ordinate and date on the abscissa, and activities are expressed in it. This scheduling chart can be positioned as a scheduling chart for construction work area. Against this, a scheduling chart for each activity with activities on the ordinate and date on the a abscissa, in which work place are expressed. and a scheduling chart for each type of job with type of job on the ordinate and date is on the abscissa, in which work place and work contents are expressed. These schectuling charts differ by method of expression, however, activity and place of work, type of job, date of execution, etc., are basically the same. Therefore, the schectuling chart for each activity or type of job can be edited based on the scheduling chart for each construction work area, as shown in Fig.13. Moreover, if the activity is executed as shown in scheduling chart, the progress status of the activity can be grasped, by cutting the schectuling chart at the present time, and editing for each construction work area, each activity, or type of job.

\subsection{Outlines of System}

This system was made by adding functions to perform progression management, to automatically edit scheduling charts for each activity, and for each type of job, to the above-mentioned scheduling system at execution stage of ordinary method construction. Therefore, this system can cope with progress management or work instructions particular to finishing work, using common functions to cope with high level process management as clean copy, resources allocation, comparative examination of structural work method of the existing scheduling system. In other words, work instructions considering duplication or omission of each activity and type of job can be made by applying a scheduling chart for each activity or scheduling chart for each type of job automatically edited on the basis of the schectuling chart for each construction work area, and grasp progress based on the schectuling chart through drawings or forms. The screen of the progress management, the output example in the scheculing chart for each construction work area and for each the type of job are shown in Fig.14, Fig.15 and Fig. 16.

At present, this system is positioned as a separate system from the above scheduling system, however, when hierarchical processing or data interlock become possible in the future, this system will be combined with the scheduling system.

\section{Conclusion}

This paper indicates the structure of the construction 


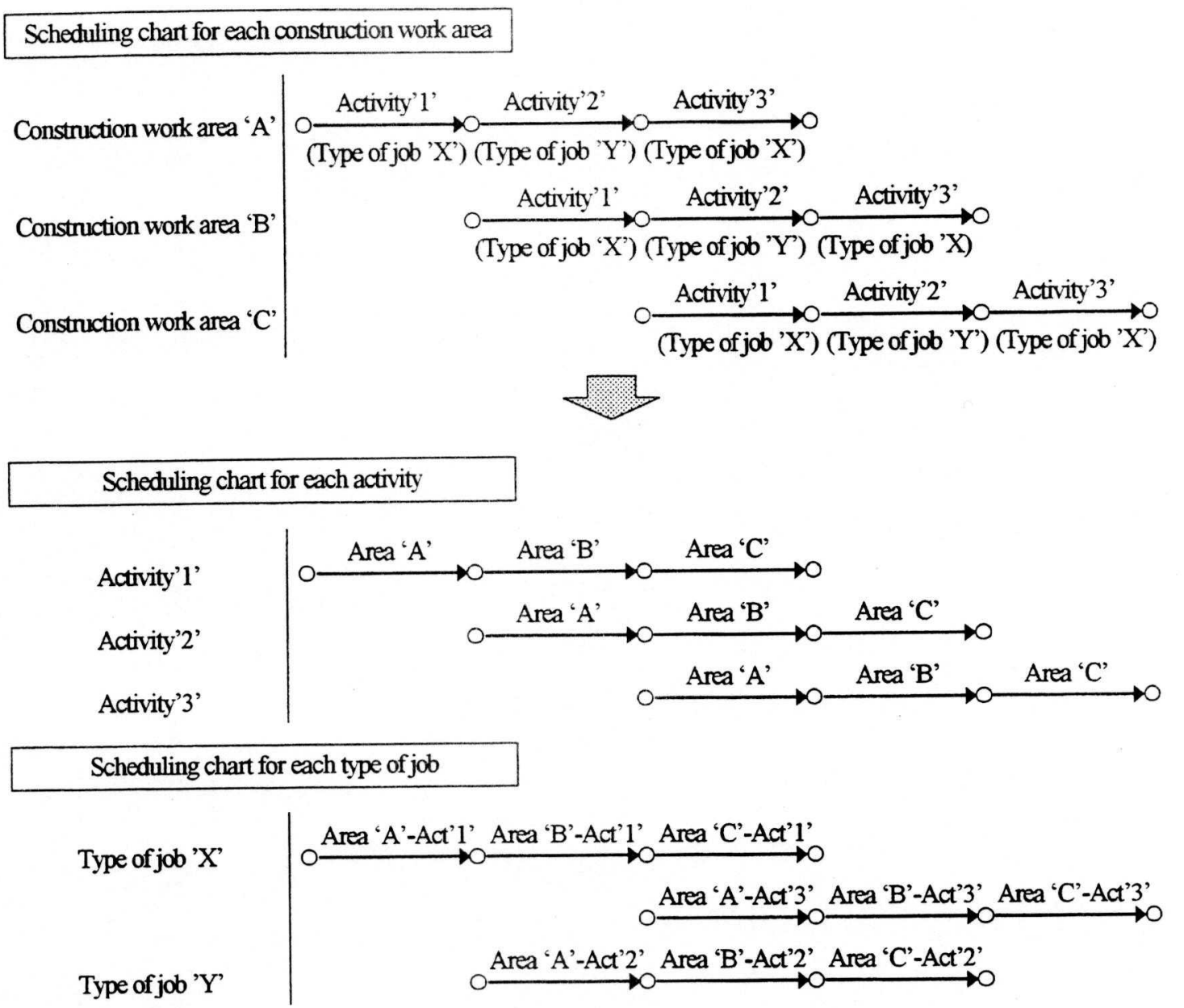

Fig.13 The method of changing the scheduling chart for each construction work area into it for each activity and each the type of job

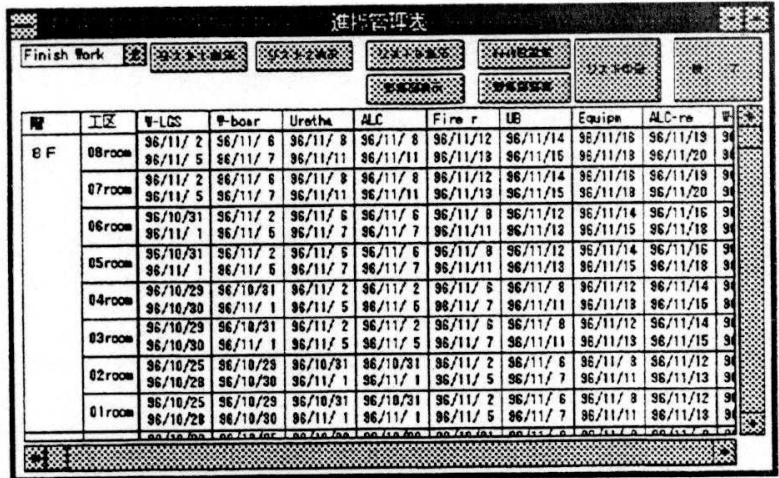

Fig.14 The screen of the progress management

scheculing, which is classified into three phases and four types of project. Also, the three systems developed acoording to this structure were outlined. These three systems were applied to actual projects, and it was confirmed they rectuce man-power of process planners and improve the quality of construction scheculing at each case

\section{References}

[1]Yuasa ,Y and Kanaiwa ,T et al.. " Schectuling System for Large-scale project at Pre-execution stage." 7th Symposizm on Organization and Management of Building Construction, Architectural Institute of Japan, pp. 103-108, 1991

[2]Yuasa, Y and Kanaiwa, $T$ et al. "Study on Method for Construction Scheduling (Partl) Structure of Construction Scheduling and A System for Framing Construction Schectuling in Large-scale project" 10 th Symposium on Organization and Management of Building Construction, Architectural Institute of Japan, pp. 441 448, 1994

[3]Yuasa , Y and Sasaki ,Y. "Study on Method for Construction Scheduling (Part2) Human-oriented System for Construction Scheduling." 11th Symposium on Organization and Management of Building Construction, Architectural Institute of Japan, pp.191 -196, 1995

[4]Yuasa ,Y and Sasaki ,Y. " A Construction Schectuling System for Finishing Work" Summaries of Technical Papers of Anmual Meeting . F-1,Anchitectural Institute of Japan, pp. 991-992, 1996 


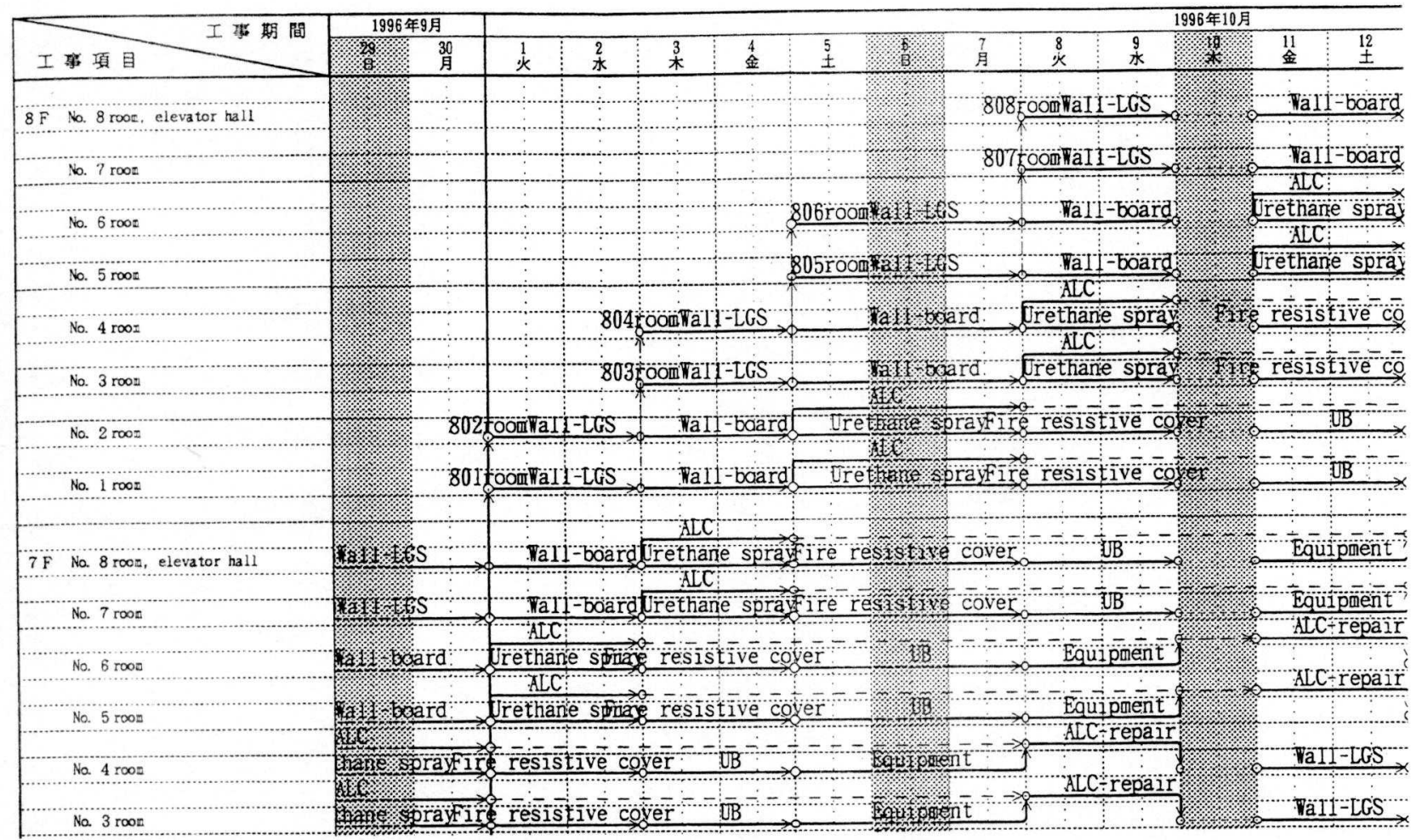

Fig.15 The output example in the scheduling chart for each construction work area

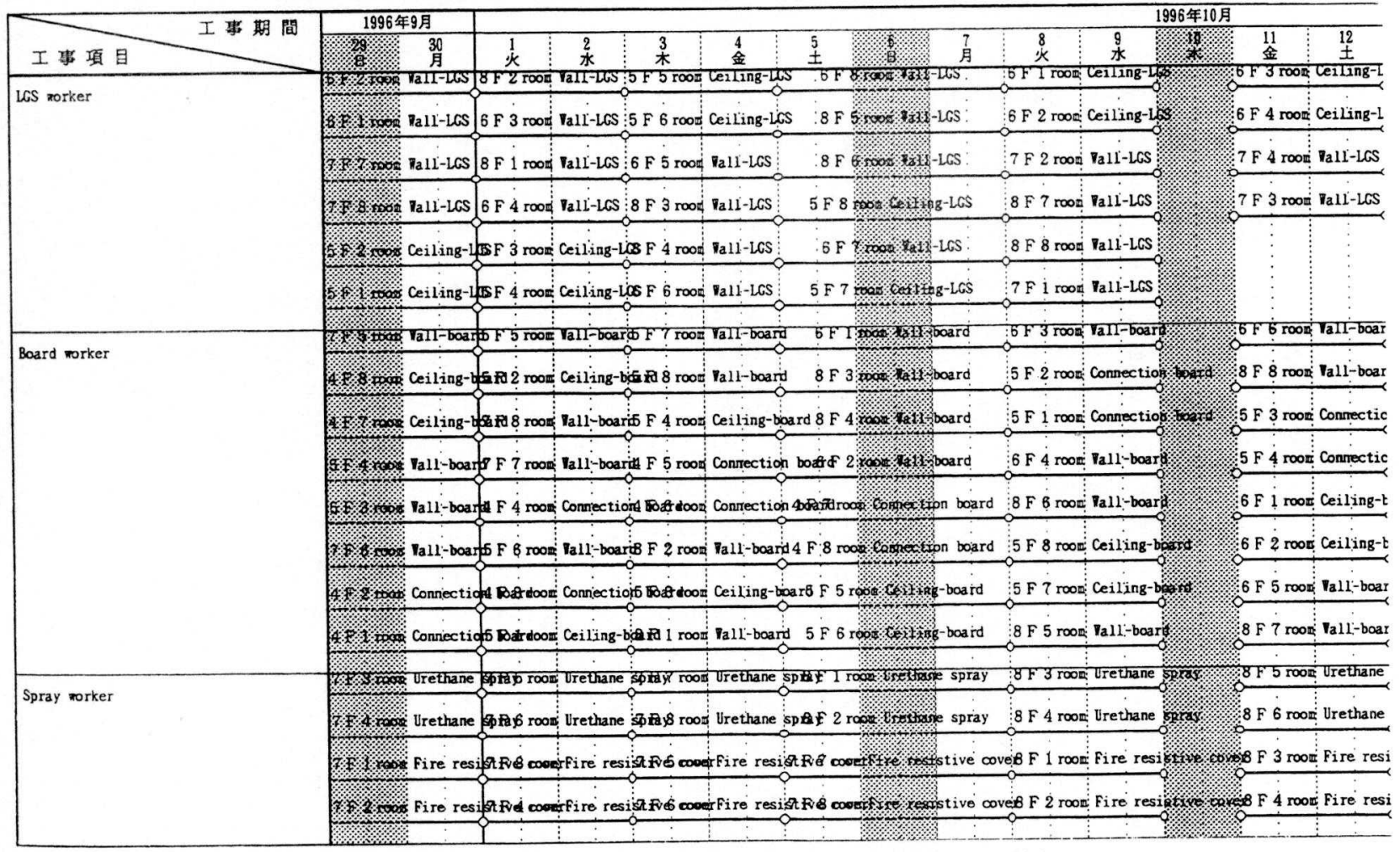

Fig.16 The output example in the schectuling chart for each type of job 